Terapia Psicológica, vol. 39, no. 3 (diciembre 202I)

\title{
Positive effects and validation of a Brief Intervention Program of Attachment-Based Compassion Therapy
}

PSICOLÓGICA

ISSN: 0718-4808
Efectos positivos y validación de un programa de intervención breve centrado en la terapia de compasión basada en los estilos de apego
Lidón Nebot-Gresa'

(iD) 0000-0003-1574-7492

gresaeuji.es

\section{Cristian Coo}

(iD) 0000-0001-9610-6413

coo@uji.es
Susana Llorens

(iD) 0000-0001-7545-5286

llorgumeuji.es
Marisa Salanova'

(iD) 0000-0001-7873-7078

salanova@uji.es

Javier Garcia-Campayo ${ }^{2}$

(iD) 0000-0002-3797-4218

jgarcamp@gmail.com

1 Universitat Jaume I, WANT Research Team, Castelló de la Plana, Spain.

2 Miguel Servet Hospital, Zaragoza, Spain.

\section{Abstract:}

Objectives: In this study, we analyzed the validation and effects of a brief intervention of Attachment-Based Compassion Therapy (ABCT). Specifically, the aim of this study was to assess the efficacy of this brief protocol in improving compassion and other related variables. Method: The intervention consists of two five-hour sessions, in a controlled trial with one intervention group (ABCT) and one control group. Before and after the intervention, a short questionnaire was administered, focused on compassion and other related variables (i.e. transcendence beliefs, happiness, endo-group solidarity, and global identity). Participants in the experimental group were 17 healthy adults (i.e., students and university teachers) attending a compassion intervention based on $\mathrm{ABCT}$. The control group was composed of 44 participants who did not attend the intervention. Results: Results showed that, compared to the control group, the brief ABCT intervention significantly improved compassion, which was the main aim of the intervention, and further analysis showed that it also significantly increased transcendence beliefs and endo-group solidarity. Moreover, the ABCT intervention were empirically validated. Conclusions: These results confirm and validate the potential of a brief ABCT intervention.

Keywords: intervention; compassion; transcendence beliefs; solidarity.

\section{Resumen:}

Objetivos: Este estudio pretende analizar la validación y los efectos de una intervención breve centrada en la Terapia de compasión basada en los estilos de apego (ABCT). Específicamente, se trata de evaluar la eficacia de este breve protocolo para mejorar la compasión y otras variables relacionadas. Método: La intervención consta de dos sesiones de cinco horas, en un ensayo controlado con un grupo de intervención $(A B C T)$ y un grupo control. Antes y después de la intervención, se administró un cuestionario, centrado en la compasión y otras variables relacionadas (creencias de trascendencia, felicidad, solidaridad endogrupal e identidad global). Los participantes en el grupo experimental fueron 17 adultos sanos (estudiantes y profesores universitarios) que asistieron a una intervención de compasión basada en ABCT. El grupo de control estuvo compuesto por 44 participantes que no asistieron a la intervención. Resultados: Los resultados mostraron que en comparación con el grupo control, la intervención breve ABCT mejoró significativamente la compasión, que era el objetivo principal de la intervención, y un análisis posterior mostró que también aumentaron significativamente las creencias de trascendencia y la solidaridad endogrupal. Además, la intervención ABCT fue validada empíricamente. Conclusiones: Estos resultados confirman y validan el potencial de una intervención breve en ABCT.

Palabras clave: intervención; compasión; creencias de trascendencia; solidaridad. 
Positive effects and validation of a Brief Intervention Program of Attachment-Based Compassion Therapy .

\section{Introduction}

Compassion is currently a key construct because caring for others and ourselves is essential in developing positive emotional states and achieving more humanity and effectiveness in organizations (Frost, 1999; Hoffmann et al., 2011; Lilius et al., 2012). In the 19th century, Victor Hugo stated that there is nothing more powerful than an idea whose time has come. This is what has occurred with the concept of compassion. Although there is previous research in the clinical field, the concepts of compassion and organization were not brought together until 1999 (Frost, 1999), thus opening up new possibilities for applied research.

Compassion refers to a process in which the human being pays attention to suffering, feels an empathic concern that allows him/her to connect emotionally with another person who is suffering, and responds compassionately, that is, performs a series of actions in order to reduce, alleviate, or make the suffering more bearable (Kanov et al., 2004). Generally, compassion has been defined as a positive construct that involves: (1) recognizing and understanding the universality of suffering, (2) feeling emotionally connected to the suffering of others, (3) tolerating uncomfortable feelings generated as part of remaining mindful and accepting the suffering of others, and (4) being motivated to act to alleviate suffering (Strauss et al., 2016).

On other hand, Gilbert (2015) defines compassion as deep awareness of the suffering of oneself and others, along with the desire to help avoid it. This author describes a multicomponent biopsychosocial approach on compassion, based on the evolution of affective behavior that leads to compassion and that supports the newer approaches to psychotherapy. Related to caring motives and the nature of attachment behaviors he states the relevance, to provide a secure base (sources of protection, validation, encouragement, and guidance) and a safe haven (source of relief and comfort) together with physiological regulatory functions. At the same time, he refers that what transforms the basic motives of care into potentials of compassion is the way in which recent human cognitive competencies give rise to different types of "mental awareness" and "conscious intentionality" (Gilbert, 2020).

Previous research has shown the existence of a series of skills and basic mechanisms that allow compassion towards others (dimensions that are based on Neff's concept of self-compassion, that is, compassion about oneself) to develop. Specifically, compassion (as well as selfcompassion), is characterized by the development of three components or psychological: (1) mindfulness (ie, mindfulness anchored in the present, here and now), (2) kindness or goodness ie, warmth and understanding towards oneself and towards others), and (3) common humanity (ie, suffering as a basic condition of human existence) (Neff, 2003; Pommier, 2011). Furthermore, Shonin et al. (2014) propose five psychological mechanisms that underlie the development of compassion: (1) positive affect (ie, affective state formed by positive emotions), (2) positive thinking (ie, the result of maintaining a positive and optimistic attitude), (3) empathy (ie, emotion that involves feeling and understanding the feelings of others), (4) the improvement of interpersonal relationships (ie, ties between two or more people) and (5) decreasing psychological distress (ie, state of emotional suffering). 
The results of previous research show that compassion is an effective basic tool for promoting well-being and reducing people's suffering (García-Campayo et al., 2017). Furthermore, compassion is also positively related to social connectivity (ie, the ability to establish links with others), and prosocial behaviors (i.e., voluntary behaviors in favor of others) (Desbordes et al., 2012, Leiberg et al., 2011) with an increase in positive affect, empathy, and interpersonal relationships (Shonin et al., 2014).

Moreover, self-compassion (ie, compassion towards oneself) is also positively related to altruistic behaviors (ie, behaviors that tend to benefit others at the expense of the individual him/herself), organizational citizenship behaviors and higher performance (Breines \& Chen, 2013; Chu, 2016; Kemeny et al., 2012; Weng et al., 2013),

For example, in a sample of 304 university students, a direct relationship between selfcompassion and subjective happiness was demonstrated (Booker \& Dusnmore, 2018). Along the same lines, another study revealed the impact of compassion on improving psychological functioning and subjective well-being (Kirby, 2017). More recently, Amutio et al. (2018), in a study with a sample of 255 people, pointed out that compassion was associated with other key variables, such as: (1) emotions (ie, fun, interested, happy, self-confident/a) and positive self-transcendence (ie, amazed, grateful, hopeful, inspired, love and closeness, serene, fascinated); (2) values of universality (eg, justice, preservation of nature, and tolerance); (3) transcendence beliefs (ie connection with everything around us); (4) endo-group solidarity (ie, subjective identification with a close and significant reference group); (5) fusion of identity (ie, image that represents relationships with people of his/her kind, and with people in general; and (6) global humanitarian identity (ie, supranational identification with humanity as a global community) and subjective well-being (ie, general well-being, eudaimonic well-being, affective well-being, and social welfare). However, although research on compassion and positive results exists, this research is still in its infancy, especially in organizational contexts.

These positive relationships can be enhanced through Compassion Based Interventions (CBls). Authors such as Kirby et al. (2017) define CBls as various standardized protocols that focus on the concept of compassion (although each from a theoretical position and based on key competences). Influenced by the Tibetan Buddhist tradition, they allow the development and cultivation of compassion and self-compassion, and they reduce suffering and increase wellbeing. These $\mathrm{CBls}$ have demonstrated their relevance in reducing anxiety and depression (Leaviss \& Uttley, 2015), decreasing chronic pain (Costa \& Pinto Gouveia, 2011), decreasing inflammatory markers in patients with fibromyalgia (Montero-Marín et al., 2019), and reducing eating disorders (Kelly \& Borairi, 2014), post-traumatic stress (Held \& Owens, 2015), and personality disorders (Lucre \& Corten, 2013).

Specifically, Compassion Therapy based on Attachment styles (Attachment-Based Compassion Therapy, ABCT) (García-Campayo \& Demarzo, 2015) consists of 8 sessions (2 and a half hours per session) and includes compassionate activities with different levels of complexity (ie, receiving and giving compassion to oneself, to friends, to unknown people, and to problematic people), mindfulness techniques, and recognition of attachment styles. The main novelty of this protocol is that it can be administered not only in people with psychiatric problems, but also in 
healthy people, and that it focuses on the attachment style: one of the most important psychological constructs to explain the interpersonal relationships of an individual (GarciaCampayo, Navarro-Gil \& Demarzo, 2016; García-Campayo et al., 2017). It is a protocol that was developed with the aim of betting on an intervention better adapted to the cultural and social characteristics of Latin countries, such as Spain. In addition, it has demonstrated its efficacy both in the clinical population (e.g., in patients with fibromyalgia and depression; Montero-Marín et al., 2018) and in non-clinical contexts (Navarro-Gil et al., 2018).

The program used to carry out the intervention consists of a brief adaptation of the $A B C T$ (García-Campayo \& Demarzo, 2015). ABCT therapy has a basic component that is attachment. This element, which already appears in other models (Neff, 2012; Gilbert, 2015) becomes the center of therapeutic intervention in the case of ABCT. According to Bartholomew and Horowitz (1991) there are 4 basic attachment styles: secure attachment style, worried, rejection and fearful attachment. Attachment styles influence our own image and that of others, so they are central in the relationship we maintain with ourselves and with others. Research has shown that it is secure attachment that predicts higher levels of success and balance (García-Campayo, 2020). The main objective of this ABCT protocol is to identify our attachment model and understand the influence on the interpersonal relationships.

Despite the effectiveness of the protocol, in some organizational contexts it is not possible to apply the traditional eight-session format due to time and financial limitations (the classic program is longer and more expensive). Therefore, it is necessary to apply an intervention that is shorter and less expensive, but also effective. Thus, the objective of the present study is to test the validation and the effects of a compassion intervention program focused on $A B C T$ (García-Campayo \& Demarzo, 2015) in a short format (two five-hour sessions) in healthy people, addressing the degree or level of compassion (ie, degree of compassion people feels towards others) and its effects on other positive constructs that previous research has found to be related to compassion. These constructs are transcendence beliefs (ie, connection with everything that surrounds us), subjective well-being or happiness (ie, degree of global wellbeing made up of general, eudaimonic, hedonic, and social well-being), endo-group solidarity (ie, subjective identification with our reference group), and global identity (ie, identification with humanity as a global community).

In this regard, we expect that, compared to the control group (CG), the participants in the $A B C T$ short format group (two five-hour sessions) will show a significant increase in compassion levels (Hypothesis l) and improvement in constructs related to compassion, such as transcendence beliefs, happiness, solidarity, and global identity (Hypothesis 2).

\section{Method}

\section{Participants and procedure}

The study sample consisted of 61 subjects divided into an experimental group (who participated in the $\mathrm{ABCT}$ brief intervention program) and a control group (who did not receive 
the intervention). They were convenience groups (with pre-post measures) belonging to different institutions. The distribution of the participants in each group was natural and not randomized. Specially, the experimental group was composed of a total of 17 people (nine students from a professional master's program and eight professors) (76\% women and $24 \%$ men) from a Spanish Public University. They participated in the intervention voluntarily without any type of financial compensation and receive information about the objective of the study. In all, $76 \%$ of the sample were women ( $24 \%$ men) with a mean age of 38.8 years (SD $=10.72)$. The inclusion criteria in the experimental group were: being part of the university community for this master's degree (the intervention in compassion was a teaching activity organized by the master) and giving informed consent. Prior to the first evaluation (pre-evaluation), the participants verified through a self-evaluation made by a structures interview that they did not have any mental disorders and were not receiving any psychiatric treatment. This interview (10 minutes) was conducted by a research collaborator, a health psychologist, a few days before the intervention. The control group was composed of 44 university students from the degree of Social Work belongs to other university institution. They voluntarily participated in the evaluation, but did not receive any intervention (passive control group). The participants did not receive any information about the objective of the study and receive an economic compensation to be invest in photocopies. In all, $75 \%$ of the sample were men and $23 \%$ women ( $2 \%$ missing values), with a mean age of 20.18 years $(S D=3.16)$. In both groups and before starting the research, they were informed about the ethical aspects of the program, as well as the confidentiality of the data. In addition, they provided informed consent for their participation in the study. An anonymous code was included in the questionnaires consisting of writing the initial of the father's name, the initial of the mother's name and the initial of the month of birth. This code that they wrote in the PRE and POST questionnaire pass was used to match the subjects. Also, the study was reviewed and approved by the Deontological Commission of the JAUME I University of Castellón de la Plana with the file number "CD / $12 / 2020 "$.

\section{Compassion program description}

The intervention program consists of a brief adaptation of the ABCT (Garcia-Campayo \& Demarzo, 2015) composed of two five-hour sessions. It was taught over a weekend by a psychiatrist specialized and trained to carry out the compassion intervention based on this approach. The sessions focused on increasing the participant's ability to be considerate and kind towards (i) him/herself and his/her own experience (specifically the experience of suffering), and (ii) others' experience of suffering. Each session consisted of a theoreticalexpository presentation and introduction component lasting approximately 60 minutes, an experiential practical component through guided meditations, and a group reflective component for group discussion. This intervention involved mindfulness practices and visualizations based on self-compassion and the attachment style generated in childhood. The structure of the two sessions was as follows: (1) Session 1: Preparing compassion, self-esteem and compassion, developing my compassionate world, and relationships and compassion; and (2) Session 2: Working on ourselves, advanced compassion, and transmitting compassion toward others. 
The detailed contents of both sessions are presented in Table 1. Participation in the intervention involved attending the two scheduled sessions. At the beginning of the first intervention session, the participants completed an initial questionnaire that evaluated the study variables. At the end of the last session, the participants completed the final questionnaire and handed it to the head of the research team.

Specifically, a short program consisting of 2 sessions of 5 hours each was carried out (see Figure 1). It was taught over a weekend by a therapist, psychiatrist, specialized and trained to carry out compassion intervention based on this approach. The sessions focused on increasing the participant's ability to be considerate and kind towards (i) himself and his own experience (specifically his experience of suffering), and (ii) towards the experience of suffering of others. Each of the sessions consisted of a theoretical-expository presentation and introduction component of approximately 60 minutes in each session, an experiential practical component through guided meditations and a group reflective component, of group discussion. This intervention involved mindfulness practices and visualizations based on self-compassion and the attachment style that was generated in childhood. The structure of the two sessions was as follows: (1) Session 1: Preparing compassion, self-esteem and compassion, developing my compassionate world and relationships and compassion and (2) Session 2: Working on ourselves, advanced compassion and transmitting compassion toward others. The detailed contents of both sessions are presented in Table 1. Participation in the intervention implied attendance at the two scheduled sessions. At the beginning of the first intervention session, the participants completed an initial questionnaire where the study variables were evaluated. At the end of the last session, the participants completed the final questionnaire and handed it over to the head of the research team.

Experimental

Group

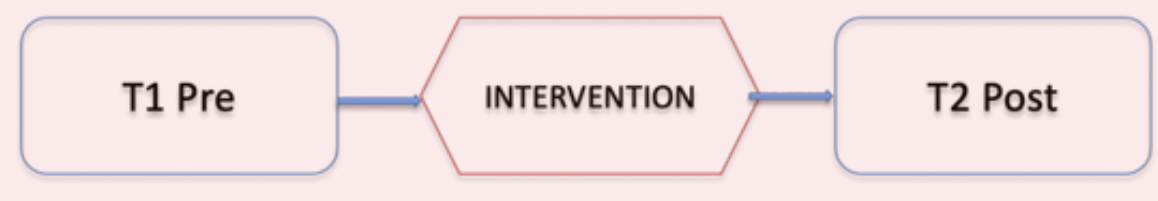

Control Group

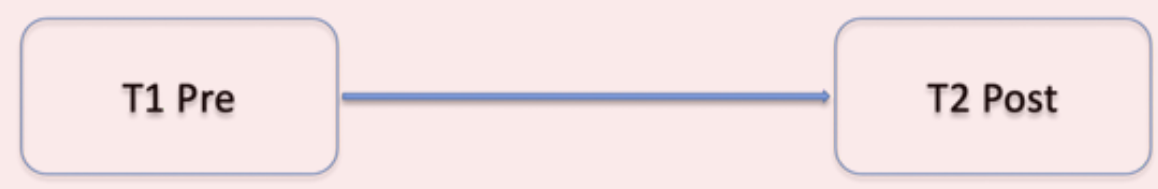

Figure 1. Intervention design. 
L. Nehot-Gresa, S. Llorens, M. Salanova, C. Coo, \& J. Garcia-Campayo.

Table 1. Specific session content and structure of the intervention program.

\begin{tabular}{|c|c|c|}
\hline $\begin{array}{l}\text { Session } \\
\text { Number }\end{array}$ & Structure & Content \\
\hline 1 & $\begin{array}{l}\text { Preparing compassion } \\
\text { Self-esteem and compassion } \\
\text { Developing my compassionate world } \\
\text { Relationships and compassion }\end{array}$ & $\begin{array}{l}\text { Theoretical aspects of brain evolution, happiness, and } \\
\text { suffering. Concept of compassion/self-compassion and } \\
\text { elimination of mistaken beliefs. Participants are instructed in } \\
\text { mindfulness practices such as breathing, and compassionate } \\
\text { body scan. These practices help to regulate attention and } \\
\text { emphasize compassionate aspects within oneself. They are a } \\
\text { core element of the program. } \\
\text { Mindfulness and compassion. Differences from self-esteem. } \\
\text { How to manage and cope with fear of compassion. Practices } \\
\text { to try to connect with affection and compassion with other } \\
\text { beings, and to try to generate feelings of security toward } \\
\text { oneself. Analysis of whether participants have previously } \\
\text { developed a mental referent figure in their life to resort to in } \\
\text { distressful situations. } \\
\text { Action mechanism of compassion. Importance of replacing } \\
\text { self- criticism with self-compassion. Development of a core } \\
\text { element of compassion such as the figure of secure } \\
\text { attachment. Replacing the critical voice with a more } \\
\text { compassionate and tolerant one. Importance of acceptance } \\
\text { in life. } \\
\text { Parenting models during childhood. Understanding that } \\
\text { relationships with parents generate different ways of relating } \\
\text { to the world. Awareness of the emotional bonds developed } \\
\text { toward parents during childhood, as well as their } \\
\text { implications for the emotional functioning in adulthood and } \\
\text { the capacity to receive affection from others. }\end{array}$ \\
\hline 2 & $\begin{array}{l}\text { Working on ourselves } \\
\text { Advanced compassion } \\
\text { Transmitting compassion toward } \\
\text { others }\end{array}$ & $\begin{array}{l}\text { Reconstruction of a secure attachment model, modifying our } \\
\text { relationships with ourselves and with others through } \\
\text { compassion. Practices to become aware of our own ability } \\
\text { to give affection to others and ourselves. Reconciliation with } \\
\text { parents (where appropriate). } \\
\text { Forgiveness and common barriers to compassion. } \\
\text { Importance of forgiveness toward oneself and others. } \\
\text { Forgiveness through meditation: ( } 1 \text { ) asking forgiveness of } \\
\text { others, (2) forgiving oneself, (3) forgiving others for wrongs } \\
\text { received. Values guide activation to reduce suffering. } \\
\text { Envy and the importance of developing an attachment } \\
\text { figure based on oneself. How to manage difficult } \\
\text { relationships. Trying to understand others' suffering in order } \\
\text { to develop applied compassion in daily life. } \\
\text { Equanimity, a quality stemming from compassion practice. } \\
\text { How to maintain compassion exercises throughout life. } \\
\text { Practices to develop equanimity: we are all the same, the } \\
\text { fallacy of categories, giving gratitude. Maintenance of } \\
\text { compassion toward others and ourselves. }\end{array}$ \\
\hline
\end{tabular}

\section{Measurements}

Compassion. We used the Compassion for others scale by Amutio et al. (2018). This scale is made up of 16 items that evaluate the degree of compassion people feel towards others on a Likerttype scale from 1 (Almost never) to 5 (Almost always). It contains four dimensions: (1) kindness (4 
items; eg, "I like to help other people who go through difficult times"); (2) common humanity (4 items; eg, "It is important to recognize that all people have weaknesses, nobody is perfect "); (3) a dimension of not-judging / forgiveness ( 4 items; eg," I try not to criticize the weaknesses or mistakes of others too much"); and (4) mindfulness (4 items; eg, "I notice when people are upset, even if they don't say anything"). The scale has adequate internal reliability (Pre $\alpha=.85$; Post $\mathrm{a}=.88$ ).

Transcendence beliefs. Cloninger's scale of transcendence beliefs was used (1994). This scale is composed of five items that assess the degree of agreement with statements about the connection we feel with what surrounds us on a Likert-type scale ranging from 1 (Strongly disagree) to 7 (Strongly agree). An example of an item is: "I have had moments of great joy when I felt deep feelings of unity with everything that exists." The scale presents adequate internal reliability (Pre $\alpha=.79$; Post $\alpha=.89$ ).

Happiness. The Pemberton Happiness Index (PHI) by Vázquez \& Hervás (2012) was used. This scale is made up of 11 items rated on a Likert-type response scale ranging from 0 (Strongly disagree) to 10 (Strongly agree) that evaluate: (1) general well-being (2 items; eg, "I feel very satisfied with my life "), (2) eudaimonic well-being (6 items; eg," My life is full of learning and challenges that make me grow "), (3) hedonic affection or well-being (2 items; eg," I enjoy many little things every day"), and (4) social welfare (1 item; eg," I feel that I live in a society that allows me to fully develop "). The scale presents adequate internal reliability (Pre $a=.87$; Post $\mathrm{a}=.90)$.

Endo-group solidarity. The endo-group solidarity scale by Leach et al. (2008) was used. This scale is made up of three items that assess subjective identification with a certain reference group (in this case, a close and very significant endo-group), rated on a Likert-type scale ranging from 1 (Strongly disagree) to 7 (Strongly agree). An example of an item is: "I feel a bond with the people in [my group]". The scale presents adequate internal reliability (Pre $a=$ .88; Post $\mathrm{a}=.88$ ).

Global Identity. The global Identity scale by De Rivera \& Carson (2015) was used. This scale is made up of seven items that measure supranational identification with humanity as a global community on a Likert-type response scale ranging from 1 (Strongly disagree) to 6 (Strongly agree). An example of an item is: "I feel like I'm living in a global village." The scale presents adequate internal reliability (Pre $\alpha=.74$; Post $\alpha=.73$ ).

\section{Data Analysis}

First, descriptive analyses (i.e., means, standard deviations), intercorrelations, and reliability analyses (Cronbach's alpha) were calculated using the SPSS statistical package.

Second, a one-way analysis of variance (ANOVA) was performed to assess whether the two groups (experimental and control) were sufficiently similar at baseline. Non-significant results of these analyses would allow the analysis of the effect of the intervention to continue, including 
post-intervention measures for both groups (experimental and control).

Third, the effects of the compassion intervention were analyzed, taking into account the group (experimental and control) and time (pre and post intervention). For this, Multivariate analyses of variance (MANOVAs) were performed with a 2x2 design (Group $x$ Time), considering the two groups (experimental and control) and the two measures of time (pre and post) for all the variables. These analyses are carried out in order to observe differences in the means on each variable depending on the group. The effect represented by the time factor (pre and post intervention) will show whether the brief compassion protocol is effective from a general approach; whereas the effect obtained according to the group (experimental and control) will show whether there are differences between the experimental and control groups at the level of the general mean. Finally, the group $x$ time interaction will show whether there are differences related to the group (whether it is experimental or control) and time.

The effect size was estimated with partial eta-squared (n2). Cohen's effect size cut-off criteria were used for descriptive purposes: $02, .13$, and .26, for small, medium, and large effects, respectively (Cohen, 1988).

\section{Results}

First, descriptive analyses show that reliability analyses of all the scales meet the criteria proposed by scientific research (Nunnally \& Bernstein, 1994) in both the pre and post intervention measures (see Table 2). Furthermore, the correlation analyses between the preintervention variables indicate that compassion correlates positively and significantly (mean $r=$ .44 , ranging from .27 to .62) with the study variables (ie, transcendence beliefs, endo-group solidarity, and global identity), except for the correlation with happiness, which is not significant (see Table 2). In addition, the correlation analyses between the post-intervention variables indicate that compassion correlated positively and significantly (mean $r=.49$ ) with the study variables (see Table 3).

Table 2. Pre-Intervention Means, Standard Deviations, Internal Consistency Reliability Coefficients, and Correlations $(n=61)$.

\begin{tabular}{lcccccccc}
\hline \multicolumn{1}{c}{ Variables } & Mean & SD & $\alpha$ & 1 & 2 & 3 & 4 \\
\hline 1. Compassion & 4.18 & .43 & .85 & - & - & - & - \\
2. Transcendence Beliefs & 4.33 & 1.26 & .79 & $.42^{* * *}$ & - & - & - \\
3. Happiness & 7.43 & 1.30 & .87 & .20 & $.42^{* * *}$ & - & - \\
7. Endo-group Solidarity & 5.85 & 1.01 & .88 & $.42^{* * *}$ & .07 & $.27^{*}$ & - \\
8. Global Identity & 4.23 & .81 & .74 & $.50^{* * *}$ & $.62^{* * *}$ & .21 & .14 \\
\hline
\end{tabular}

Compassion (1=Minimum;5=Maximum), Transcendence Beliefs ( $1=$ Minimum;7=Maximum), Happiness ( $0=$ Minimum;10=Maximum), Endo-group Solidarity (1=Minimum;7=Maximum), Global Identity (1=Minimum;6=Maximum) ${ }^{*}, p<.05 ; * * *, p<.001$. 
Table 3. Post Intervention Means, Standard Deviations, Internal Consistency Reliability Coefficients, and Correlations ( $n=61)$.

\begin{tabular}{lcccccccc}
\hline \multicolumn{1}{c}{ Variables } & Mean & SD & $\alpha$ & 1 & 2 & 3 & 4 \\
\hline (1) Compassion & 4.31 & .43 & .88 & - & - & - & - \\
(2) Transcendence Beliefs & 4.58 & 1.49 & .89 & $.58^{* * *}$ & - & - & - \\
(3) Happiness & 7.62 & 1.37 & .90 & $.41^{* *}$ & $.42^{* * *}$ & - & - \\
(4) Endo-group Solidarity & 5.81 & .98 & .88 & $.45^{* * *}$ & $.43^{* * *}$ & $.61^{* *}$ & - \\
(5) Global Identity & 4.42 & .80 & .73 & $.52^{* * *}$ & $.63^{* * *}$ & $.40^{* * *}$ & $.42^{* * *}$ \\
\hline
\end{tabular}

Compassion (1=Minimum;5=Maximum), Transcendence Beliefs (1=Minimum;7=Maximum), Happiness

( $0=$ Minimum;10=Maximum), Endo-group Solidarity (1=Minimum;7=Maximum), Global Identity

(1=Minimum;6=Maximum), ${ }^{* \star *}, p<.001$.

The results of the baseline ANOVA test showed no significant differences between the groups on Compassion $[F(1,58)=0.774, p=.383]$, Transcendence Beliefs $[F(1,58)=2.995, p=.089]$, Endo-group Solidarity $[F(1,58)=2.158, p=.147]$, or Global Identity $[F(1,58)=1.645, p=.205]$. Results indicated significant differences between the intervention and control group on Happiness $[F(1,58)=12.360, p<.001]$, in favor of the intervention group, thus impeding the comparison of happiness in the groups. Consequently, happiness was not included in the following analyses.

Mean scores and standard deviations per group and time as well as per group $x$ time are shown in Table 4, and the summary results of baseline one-way ANOVAs between groups are found in Table 5.

Table 4. Pre - Post Intervention and Control Groups Scores- Mean (SD)

\begin{tabular}{lcccc}
\hline & \multicolumn{2}{c}{ Intervention $(\mathrm{n}=17)$} & \multicolumn{2}{c}{ Control $(\mathrm{n}=43)$} \\
\hline & Pre & Post & Pre & Post \\
\hline (1) Compassion & $4.2(0.5)$ & $4.6(0.2)$ & $4.1(0.3)$ & $4.1(0.4)$ \\
(2) Transcendence Beliefs & $4.7(1.4)$ & $5.6(1.2)$ & $4.1(1.1)$ & $4.1(1.3)$ \\
(3) Happiness & $8.3(1.0)$ & $8.9(0.6)$ & $7.1(1.2)$ & $7.2(1.2)$ \\
(4) Endo-group Solidarity & $6.1(0.9)$ & $6.4(0.4)$ & $5.7(1.0)$ & $5.5(1.0)$ \\
(5) Global Identity & $4.4(0.8)$ & $4.8(0.7)$ & $4.1(0.8)$ & $4.2(0.7)$ \\
& & & & \\
\hline
\end{tabular}

Compassion (1=Minimum;5=Maximum), Transcendence Beliefs (l=Minimum;7=Maximum), Happiness ( $0=$ Minimum;10=Maximum), Endo-group Solidarity (1=Minimum;7=Maximum), Global Identity (1=Minimum;6=Maximum) 
Table 5. Pre-Intervention one-way ANOVAs with group as comparison factor.

\begin{tabular}{lcccc}
\hline & \multicolumn{5}{c}{ Time } \\
\hline & $\mathrm{df}_{\text {effect }}$ & $\mathrm{df}_{\text {error }}$ & $\mathrm{F}$ & $P$ \\
\hline (1) Compassion & 1 & 58 & .774 & .383 \\
(2) Transcendence Beliefs & 1 & 58 & 2.995 & .089 \\
(3) Happiness & 1 & 58 & 12.360 & .001 \\
(4) Endo-group Solidarity & 1 & 58 & 2.158 & .147 \\
(5) Global Identity & 1 & 58 & 1.645 & .205 \\
\hline
\end{tabular}

Compassion (1=Minimum;5=Maximum), Transcendence Beliefs (l=Minimum;7=Maximum), Happiness $(0=$ Minimum;10=Maximum), Endo-group Solidarity (1=Minimum;7=Maximum), Global Identity

(1=Minimum;6=Maximum)

Results of the MANOVAs indicate a statistically significant and large effect size for the differences between groups, $[F(5,54)=5.091, p<.001, \eta 2=.320]$, a statistically significant and large effect size for time, $[F(5,54)=4.807, p<.001, \eta 2=.308]$, and a statistically significant and large effect size for the interaction term time ${ }^{*}$ group $[F(5,54)=3.451, p<.01, \eta 2=.242]$. Results suggest significant changes in groups across time (pre and post), across groups (experimental and control), and across the time* group interaction. Taking into account the time* group interaction, follow-up ANOVAs for each of the variables indicate statistically significant differences between groups on Compassion $[F(1,58)=10.800, p<.01, \eta 2=.157]$, Transcendence Beliefs $[F(1,58)=9.089, p<.01, \eta 2=.145]$, and Endo-group Solidarity $[F(1,58)=$ $4.243, p<.05, \eta 2=.068$ ], suggesting that the intervention group increased compassion, transcendence beliefs, and endo-group solidarity from $\mathrm{T} 1$ to $\mathrm{T} 2$, unlike the control group. Results of the time* group interaction ANOVAs were non-significant for Global Identity [F (1, $58)=3.521, p=.066, \eta 2=.057]$. Although previous analyses of Happiness indicated significant differences between the intervention and control groups before the intervention (in favor of the intervention group), further analyses revealed that, considering the time* group interaction, the intervention group also increased their happiness more than the control group. A summary of the follow-up ANOVA results is shown in Table 6 and Figure 2.

Table 5. Pre-Intervention one-way ANOVAs with group as comparison factor.

\begin{tabular}{|c|c|c|c|c|c|c|c|c|c|c|c|c|c|c|c|}
\hline & \multicolumn{5}{|c|}{ Time } & \multicolumn{5}{|c|}{ Group } & \multicolumn{5}{|c|}{ Time*Group } \\
\hline & $d f_{\text {effect }}$ & $d f_{\text {error }}$ & $\mathrm{F}$ & $P$ & $n 2$ & $d f_{\text {effect }}$ & $d f_{\text {errot }}$ & $\mathrm{F}$ & $P$ & $n 2$ & $d f_{\text {effect }}$ & $d f_{\text {errot }}$ & $\mathrm{F}$ & $P$ & $\eta 2$ \\
\hline Compassion & 1 & 58 & 13.077 & .001 & .184 & 1 & 58 & 6.383 & .014 & .099 & 1 & 58 & 10.800 & .002 & .157 \\
\hline Transcendence Beliefs & 1 & 58 & 10.755 & .002 & .156 & 1 & 58 & 8.867 & .004 & .133 & 1 & 58 & 9.089 & .003 & .145 \\
\hline Happiness & 1 & 58 & 6.475 & .014 & .100 & 1 & 58 & 22.548 & .000 & .280 & 1 & 58 & 5.261 & .021 & .088 \\
\hline Endo-group Solidarity & 1 & 58 & 0.297 & .588 & .005 & 1 & 58 & 7.743 & .007 & .118 & 1 & 58 & 4.243 & .044 & .068 \\
\hline Global Identity & 1 & 58 & 7.115 & .010 & .109 & 1 & 58 & 6.095 & .017 & .095 & 1 & 58 & 3.521 & .066 & .057 \\
\hline
\end{tabular}

Compassion (l=Minimum;5=Maximum), Transcendence Beliefs ( $1=$ Minimum;7=Maximum), Happiness ( $0=$ Minimum;10=Maximum), Endo-group Solidarity (l=Minimum;7=Maximum), Global Identity (1=Minimum;6=Maximum) 


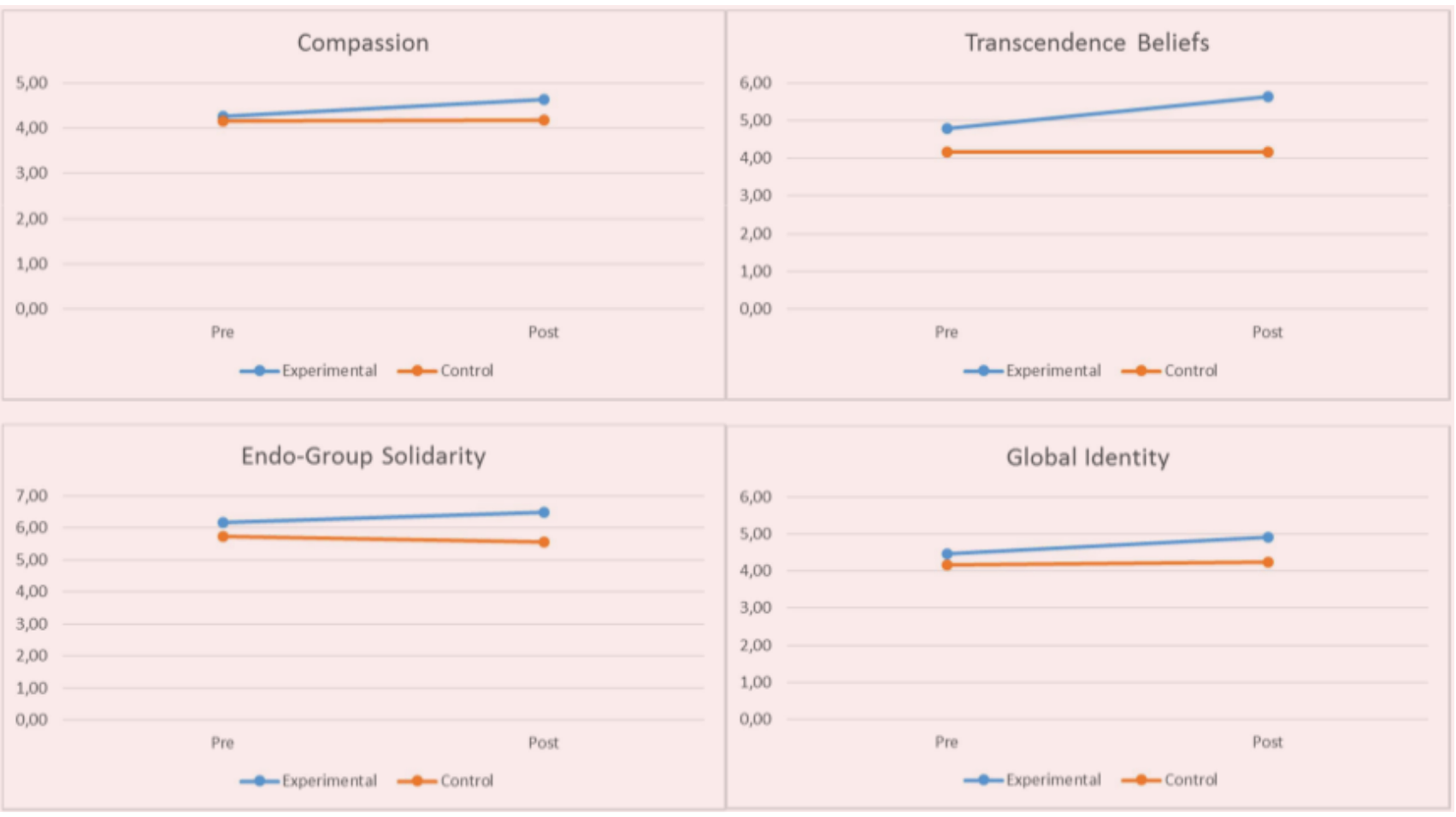

Figure 2. Line plots showing the impact of the time factor (pre, post) on dependent variables between groups.

\section{Discussion}

The objective of the present study was to experimentally test the validation and the effect, in healthy people, of the application of a compassion intervention program, consisting of the ABCT (García-Campayo \& Demarzo, 2015) in a brief format (two five-hour sessions), on compassion (ie, degree of compassion people feel towards others) and other positive constructs, such as transcendence beliefs, subjective well-being or happiness, endo-group solidarity, and global identity. Thus, we expected that, compared to the control group (CG), the participants in the ABCT brief format group (two five-hour sessions) would show a significant increase in compassion levels (Hypothesis l) and other positive constructs such as transcendence beliefs, happiness, solidarity, and global identity (Hypothesis 2).

In a sample of 61 subjects divided into an experimental group that received the brief compassion intervention (17 people from a Spanish Public University) and a control group (44 university students) that received no intervention, the results showed the effectiveness and the validation of the short version of the ABCT. Taking the group * time interaction into account, the results showed that the short version of the $A B C T$ is effective in increasing levels of compassion and other related constructs such as transcendence beliefs and endo-group solidarity. In this regard, the experimental subjects, compared to the control group, showed significant differences in these constructs over time, increasing their levels of compassion, transcendence beliefs, and endo-group solidarity. The happiness variable could not be considered in the subsequent MANOVA analyses because the results of the ANOVAs performed 
in both groups (experimental and control) before starting the intervention showed significant differences in the PRE scores between the two groups (experimental and control). However, time * group analysis revealed higher levels of happiness in the group that received the intervention. Finally, and contrary to expectations, there were no significant differences, taking into account the group * time interaction, in global identity, possibly due to the type of sample used in the present study or its size. It seems that, regardless of the intervention, the subjects show similar scores on the ability to identify with people, and an intervention is not necessary in order for these levels to increase. Based on these results, Hypothesis 1 is completely fulfilled, whereas Hypothesis 2 is partially fulfilled.

The results obtained in the study are consistent with those obtained in other previous studies related to compassion. For example, ABCT compassion therapy is also valid in a healthy population, and it is a tool to promote people's well-being (García-Campayo et al., 2017). It has been positively related to other positive constructs such as social connectivity (Neff et al., 2008), positive affect, empathy and interpersonal relationships (Shonin et al., 2014), self-pity and prosocial behaviors (Breines \& Chen, 2013; Kemeny et al., 2012), altruistic behaviors (Weng et al., 2013), subjective happiness (Booker \& Dusnmore, 2018), and psychological functioning and subjective well-being (Kirby, 2017). Finally, compassion has been related to other key variables, such as emotions, positive self-transcendence, the values of universality, transcendence beliefs, endo-group solidarity, identity fusion, global humanitarian identity, and subjective well-being (Amutio et al., 2018).

In addition to these results, the novelty of the present study is that it revealed the validity and effectiveness of the ABCT in its short format (two five-hour sessions) in fostering compassion and other related positive constructs. These results, along with other brief interventions related to other positive constructs such as mindfulness, reveal the need to continue to investigate the application of these brief protocols to the reality of the organizational context (see Coo \& Salanova, 2017; Salanova et al., 2013). Although the efficacy of shorter versions of traditional CBls has not yet been demonstrated in the long term, the findings of this study suggest that it is possible to use these abbreviated interventions without losing efficacy and efficiency. They are a very useful and time-efficient way of operatively introducing compassion as a healthy organizational practice (Salanova et al., 2013) that has the potential to promote healthy organizational results. In addition, we must mention the relevance of the attachment component in the intervention. It adds a plus referred to the effect of training on attachment style. Results evidence that the secure attachment style (as opposed to the insecure one), correlates with better well-being, acquisition of social skills and the development of social identity (García Campayo, 2020).

\section{Limitations and future research}

The present study has four relevant limitations. The first limitation refers to the use of selfreport measures. Thus, it would be interesting to use measures from different stakeholders (users, colleagues, supervisor). The second limitation refers to the size of the study samples. These are small samples, but they tend to reflect the reality of the current economic context, 
where SMEs are the basis of the business fabric. Another limitation is related to the lack of medium- and long-term follow-up measures that would allow us to know the effectiveness of the brief compassionate intervention over time. Finally, the last limitation has to do with the fact that the study design is not randomized and a passive control group has been included. The disadvantages of assigning experimental and control subjects in a non-random way are the following: (1) the results obtained from the intervention may depend to a greater extent on the application that the researcher makes of the intervention, (2) it increases the difficulty that the initial characteristics before treatment between the two groups are similar, (3) which may make the results not so reliable, (4) it makes it difficult to demonstrate that the intervention carried out is solely responsible of the effects obtained between the control and experimental group (Zurita-Cruz et al., 2018). Despite of that, in the context of work sometimes it is difficult to apply Positive Psychological Interventions with a randomized designs since the characteristics and the nature of the companies' settings (Randall, Griffiths \& Cox, 2005). In those situations, it is needed to done a quasi experiment. According to Cook and Campbell (1979) and Shadish et al. (2002) can be done to refer to designs that they do not use randomization to create comparisons of interest, but use statistical techniques to explain possible threats to causal inferences, such as initial differences between treatment environments; for example, differences in means of study variables between groups. Specifically in our study, the similarity of the scores between the two groups was evaluated by Analysis of Variance and the variable in which significant differences were shown before the intervention between the two groups was discarded from the subsequent analyzes (this was the case of the variable Happiness).

Future research should use high-level randomized controlled trials with larger samples and active control group intervention programs. Following this approach would be a necessary step in validating the effectiveness of short versions of compassionate interventions. This would allow us to more confidently validate short compassionate interventions as strategies to generate happy and productive workers.

Another very important aspect, as the next step in this study, would be to include other more objective outcome variables (eg, performance / performance, quality of service) and use different key agents (employees, supervisors, users / clients), taking into account the gender and age perspective in order to verify that the intervention has the same effects on men and women regardless of age. Finally, the use of long-term follow-up measures for both groups (experimental and control) would be the key to studying adherence to the brief intervention and the maintenance of its effects.

\section{Final note}

This compassionate intervention, although brief, has proven effective in improving compassion and other positive variables that can make sense of our lives. We must take our ability to pay attention to suffering seriously, put ourselves in the place of the person who is suffering, and join hands, through concrete actions, to make this suffering more bearable. 


\section{Acknowledgments}

This study was supported by a grant from Ministerio de Economía y Competitividad. Gobierno de España (\#PSI2015-64933-R) and Universitat Jaume I (UJl-B2017-81).

\section{References}

Amutio, A., Pizarro, J.J., Basabe, N., Telletxea, S., \& Harizmendi, M. (2018). Propiedades psicométricas de la Escala de Compasión hacia los Demás. PsyCap, 4, 24-37. https://tinyurl.com/2p8nwaf9

Bartholomew, K., \& Horowitz, L. M. (1991). Attachement styles among young adults a test of fourcategory model. Journal of Personality and Social Psychology, 61(2), 226-244. https://doi.org/gjm

Booker, J.A., \& Dusnmore, J.C. (2018). Testing Direct and Indirect Ties of Self-Compassion with Subjective Well-Being. Journal of Happiness Studies, 20, 1563-1585. https://doi.org/gf2bxw

Breines, J.G., \& Chen, S. (2013). Activating the inner caregiver. The role of support-giving schemas in increasing state self-compassion. Journal of Experimental Social Psychologist, 49(1), 5864. https://doi.org/10.1016/j.jesp.2012.07.015

Chu, L.C. (2016). Mediating positive moods: the impact of experiencing compassion at work. Journal of Nursing Management, 24(1), 59-69. https://doi.org/10.1111/jonm.12272

Cloninger, C.R. (1994). Temperament and personality. Current opinion in neurobiology, 4(2), 226273. https://doi.org/10.1016/0959-4388(94)90083-3

Cohen, J. (1988). Statistical Power Analysis for the behavioral sciences (2nd ed.). Routledge. https://doi.org/10.4324/9780203771587

Coo, C., \& Salanova, M. (2017). Mindfulness can make you Happy-and-Productive: A Mindfulness Controlled Trial and Its Effects on Happiness, Work Engagement and Performance. Journal of Happiness Studies, 19, 1691-1711. https://doi.org/hdb3

Cook, T. D., \& Campbell, D.T., (1979). Quasi-experimentation: Design and Analyses Issues for Field Settings. Houghton Mifflin.

Costa, J., \& Pinto-Gouveia, J. (2011). Acceptance of pain, self-compassion and psychopathology: using the chronic pain acceptance questionnaire to identify patients subgroups. Clinical Psychology Psychotherapy, 18(4), 292-302. https://doi.org/10.1002/cpp.718

Desbordes, G., Negi, L.T., Pace, T.W., Wallace, B.A., Raison, C.L., \& Schwartz, E.L., (2012). Effects of mindfulattention and compassion meditation training on amygdala response to emotional stimuli in an ordinary, non-meditative state. Frontiers in Human Neuroscience, 6, 292. https://doi.org/gg9kk8 
Positive effects and validation of a Brief Intervention Program of Attachment-Based Compassion Therapy.

Frost, P. J. (1999). Why compassion counts! Journal of Management Inquiry, 8(2), 127-133. https://doi.org/10.1177/105649269982004

Garcia-Campayo, J., \& Demarzo, M. (2015). Mindfulness y compassion. La nueva revolución. Siglantana.

Garcia-Campayo, J., Demarzo, M., \& Modrego, M. (2017). Bienestar emocional y mindfulness en la educación. Alianza.

Garcia-Campayo, J., Navarro-Gil M., \& Demarzo, M. (2016). Attachment-based com-passion therapy. Mindfulness Compassion, 1(2), 68-74. https://doi.org/hdb6

Garcia-Campayo, J. (2020). La práctica de la compasión. Singlantana.

Gilbert, P. (2015). Terapia centrada en la compassion. Desclée de Brouwer.

Gilbert, P. (2020). Compassion: From Its Evolution to a Psychotherapy. Frontiers Psychology, 11. https://doi.org/10.3389/fpsyg.2020.586161

Held, P., \& Owens, G.P. (2015). Effects of self-compassion work-book training on trauma-related guilt in a sample of homeless veterans: a pilot study. Journal of Clinical Psychology, 71(6), 513-526. https://doi.org/10.1002/jclp.22170

Hoffmann, S.G., Grossman, P., \& Hinton, D.E. (2011). Loving-Kindness and compassion meditation: potential for psychological interventions. Clinical Psychology Review, 31(7), 1126-32. https://doi.org/10.1016/j.cpr.2011.07.003

Kanov, J., Maitlis, S., Worline, M.C., Dutton, J.E., Frost, P.J., \& Lilius, J.M. (2004). Compassion in organizational life. American Behavioral Scientist, 47(6), 808-827. https://doi.org/dqrz2r

Kelly, A., \& Borairi, S. (2014). Are improvements in shame and self-compassion early in eating disorders treatment associated with better patient outcomes? Journal Eating Disorders, 47(1), 54-64. https://doi.org/10.1002/eat.22196

Kemeny, M. E., Foltz, C., Cavanagh, J. F., Cullen, M., Giese-Davis, J., Jennings, P., Rosenberg, E. L., Gillath, O., Shaver, P. R., Wallace, B. A., \& Ekman, P. (2012). Contemplative/emotion training reduces negative emotional behavior and promotes prosocial responses. Emotion, 12(2), 338-350. https://doi.org/10.1037/a0026118

Kirby, J.N. (2017). Compassion interventions: The programmes, the evidence, and implications for research and practice. The British Psychological Society Psychology and Psychotherapy: Theory, Research and Practice, 90(3), 432-455. https://doi.org/gj7q62

Kirby, J.N., Tellegen, C.N, \& Steindl, S.L. (2017). A Meta-Analysis of Compassion-Based Interventions: Current State of Knowledge and Future Directions. Behavior Therapy, 48(6), 778-792. https://doi.org/gch9tf 
Leach, C.W., Wan Zomeren, M., Zebel, S., Vliek, M., Pennekamp, S.F., Doosje, B., Ouwerkerk, J.P., \& Spears, R. (2008). Group-level self-definition and self-investment: a hierarchical (multicomponent) model of in-group identification. Journal of Personality and Social Psychology, 95(1), 144-165. https://doi.org/fmq589

Leaviss, J.\& Uttley, L. (2015). Psychotherapeutic benefits of compassion-focused therapy: An early systematic review. Psychological Medicine, 45(05), 927-945. https://doi.org/f65rj5

Leiberg, S., Klimecki, O., \& Singer, T. (2011). Short-Term Compassion Training Increases Prosocial Behavior in a Newly Developed Prosocial Game. Plos one. 6 (3). https://doi.org/b9snvr

Lilius, J.M., Kanov, M.C., Dutton, J.E., Worline, M.C., \& Maitlis, S. (2012). Compassion revealed: What we know about compassion at work and where We need to know more. In K. Cameron and G. Spreitzer (eds.), Oxford Handbook of positive Organizational Scholarship (pp. 273-287). Oxford University Press. https://doi.org/hdb8

Lucre, K.M., \& Corten, N. (2013). An exploration of group compassion-focused therapy for personality disorder. Psychology and Psychotherapy, 86(4), 387-400. https://doi.org/f5g7g7

Montero-Marín, J., Andrés-Rodriguez, L., Tops, M., Luciano, J.V., Navarro-Gil, M., Feliu-Soler, A., López del Hoyo, Y., \& Garcia-Campayo, J. (2019). Effects of 'attachment-based compassion therapy' (ABCT) on brain-derived neurotrophic factor and low-grade inflammation among fibromyalgia patients: A randomized controlled trial. Scientific Reports, 9, 15639. https://doi.org/10.1038/s41598-019-52260-z

Montero-Marín, J., Navarro-Gil, M., Puebla-Guedea, M., Luciano, J. V., Van Gordon, W., Shonin, E., \& Garcia-Campayo, J. (2018). Efficacy of 'attachment-based compassion therapy' $(A B C T)$ in the treatment of fibromialgia: a randomized controlled trial. Frontiers in Psychiatry, 8, 307. https://doi.org/10.3389/fpsyt.2017.00307

Navarro-Gil, M., López del Hoyo, Y., Modrego-Alarcón, M., Montero-Marín, J., Van Gordon, W., Shonin, E., \& Garcia Campayo, J. (2018). Effects of Attachment Based Compassion therapy $(A B C T)$ on Self-compassion and Attachment Style in Healthy People. Mindfulness, 11, 51-62. https://doi.org/10.1007/s12671-018-0896-1

Neff, K.D. (2003). Self-compassion: An alternative conceptualization of a healthy attitude toward oneself. Self and identity, 2(2), 85-101. https://doi.org/dsthm2

Neff, K.D., Pisitsungkagarn, K., \& Hseih, Y. (2008). Self-compassion and self-construal in the United States, Thailand and Taiwan. Journal of Cross-Cultural Psychology, 39(3), 267285. https://doi.org/b2dptg

Neff, K. (2012). Sé amable contigo mismo. El arte de la compasión hacia uno mismo. Oniro. 
Nunnally, J. C., \& Bernstein, I. R. (1994). Psychometric Theory. McGraw-Hill.

Pommier, E.A. (2011). The compassion scale. Dissertation Abstracts International Section A: Humanities and Social Sciences, 72(4), 1174.

Randall, R., Griffiths, A. \& Cox, T. (2005). Evaluating organizational stress-management interventions using adapted study designs. European Journal of Work and Organizational Psychology, 14(1), 23-41. https://doi.org/10.1080/13594320444000209

De Rivera, J. \& Carson, H.A. (2015) Cultivating a Global Identity. Journal of Social and Political Psychology, 3(2), 310-330. https://doi.org/10.5964/jspp.v3i2.507

Salanova, M., Llorens, S., Acosta, H., \& Torrente, P. (2013). Positive interventions in Positive Organizations. Terapia Psicológica, 31(1), 101-113. https://doi.org/f4qn3r

Shadish, W. R., Cook, T. D., \& Campbell, D. T. (2002). Experimental and Quasi-Experimental Designs for Generalized Causal Inference. Houghton, Mifflin and Company.

Shonin, E., Van Gordon, W., Compare, A., Zangeneh, M., \& Griffiths, M. (2014). Buddhist-derived loving-kindness and compassion meditation for the treatment of psychopathology: a systematic review. Mindfulness, 6(5), 1161-118. https://doi.org/10.1007/s12671-014-0368-1

Strauss, C., Lever Taylor, B., Gu, J., Kuyken, W., Baer R, Jones F.\& Cavanagh, K. (2016). What is compassion and how can we measure it? A review of definitions and measures. Clinical Psychology Review, 47,15-27. https://doi.org/dghv

Vazquez, C. \& Hervás, G. (2012). Addressing current challenges in cross-cultural measurement of well-being: The Pemberton Happiness Index. In A. Delle Fave, \& H.H. Koop (Eds.), WellBeing and Cultures: perspectives from Positive Psychology (pp. 31-49). Springer. https://doi.org/hdch

Weng, H.Y., Fox, A.S., Shackman, A.J., Stodola, D.E., Caldwell, J.Z.K., Olson, M.C., Rogers, G. M. \& Davidson, R.J. (2013). Compassion training alters altruism and neural responses to suffering. Psychological Science, 24(7), 1171-1180. https://doi.org/f44knf

Zurita-Cruz, J.N., Márquez-González, \& Miranda-Novales, \& Villasís-Keever, M.A. (2018). Estudios experimentales: diseños de investigación para la evaluación de intervenciones en la clínica. Revista Alergia México, 65(2), 178-186. https://doi.org/hdcm

\section{Para citar en APA}

Nebot-Gresa, L., Llorens, S., Salanova, M., Coo, C., \& Garcia-Campayo, J. (2021). Positive effects and validation of a Brief Intervention Program of Attachment-Based Compassion Therapy. Terapia Psicológica (En línea), 39(3), 427-444. https://doi.org/10.4067/S0718-48082021000300427 